(6) OPEN ACCESS

\title{
Platelet-rich plasma does not enhance return to play in hamstring injuries: a randomised controlled trial
}

\author{
Bruce Hamilton, ${ }^{1,2}$ Johannes L Tol, ${ }^{2}$ Emad Almusa, ${ }^{3}$ Sirine Boukarroum, ${ }^{2}$ \\ Cristiano Eirale, ${ }^{2}$ Abdulaziz Farooq, ${ }^{4}$ Rodney Whiteley, ${ }^{5}$ Hakim Chalabi ${ }^{6}$
}

\begin{abstract}
- Additional material is published online only. To view please visit the journal online (http://dx.doi.org/10.1136/ bjsports-2015-094603).

${ }^{1}$ High Performance Sport NZ, Millennium Institute of Sport and Health, Auckland, New Zealand

${ }^{2}$ Department of Sports Medicine, Aspetar, Doha, Qatar

${ }^{3}$ Department of Radiology,

Aspetar, Doha, Qatar

${ }^{4}$ Athlete Health and

Performance Research, Aspetar, Doha, Qatar ${ }^{5}$ Department of Rehabilitation, Aspetar, Doha, Qatar ${ }^{6}$ Director General for International Medical Affairs and Programs \& Centers of Excellence, Aspetar, Doha, Qatar
\end{abstract}

\section{Correspondence to}

Dr Bruce Hamilton,

High Performance Sport NZ,

Millennium Institute of Sport and Health, Auckland, New Zealand 0632; bruce. hamilton@hpsnz.org.nz

Accepted 2 May 2015

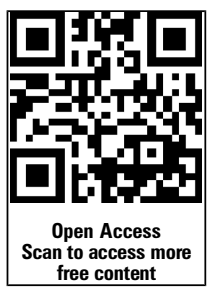

CrossMark

To cite: Hamilton $B$, Tol JL, Almusa $\mathrm{E}$, et al. Br J Sports Med 2015;49:943-950.

\section{ABSTRACT}

Background To evaluate the efficacy of a single platelet-rich plasma (PRP) injection in reducing the return to sport duration in male athletes, following an acute hamstring injury.

Methods A randomised, three-arm (double-blind for the injection arms), parallel-group trial, in which 90 professional athletes with MRI positive hamstring injuries were randomised to injection with PRP-intervention, platelet-poor plasma (PPP-control) or no injection. All received an intensive standardised rehabilitation programme. The primary outcome measure was time to return to play, with secondary measures including reinjury rate after 2 and 6 months.

Results The adjusted HR for the PRP group compared with the PPP group was $2.29(95 \% \mathrm{Cl} 1.30$ to 4.04$)$ $p=0.004$; for the PRP group compared with the no injection group $1.48(95 \% \mathrm{Cl} 0.869$ to 2.520$) \mathrm{p}=0.15$, and for the PPP group compared with the no injection group $1.57(95 \% \mathrm{Cl} 0.88$ to -2.80$) \mathrm{p}=0.13$. The adjusted difference for time to return to sports between the PRP and PPP groups was -5.7 days $(95 \% \mathrm{Cl}-10.1$ to -1.4$) \mathrm{p}=0.01$; between the PRP and no injection groups -2.9 days $(95 \% \mathrm{Cl}-7.2$ to 1.4$) \mathrm{p}=0.189$ and between the PPP and no injection groups 2.8 days (95\% $\mathrm{Cl}-1.6$ to 7.2$) \mathrm{p}=0.210$. There was no significant difference for the secondary outcome measures. No adverse effects were reported.

Conclusions Our findings indicate that there is no benefit of a single PRP injection over intensive rehabilitation in athletes who have sustained acute, MRI positive hamstring injuries. Intensive physiotherapy led rehabilitation remains the primary means of ensuring an optimal return to sport following muscle injury.

Trial registration number ClinicalTrials.gov Identifier: NCT01812564.

\section{INTRODUCTION}

Hamstring muscle strain injuries are one of the most common injuries in sport, with a significant morbidity for elite athletes. ${ }^{1-3}$ Despite acute muscle injuries accounting for up to one-third of all timeloss injuries and being associated with a reinjury rate of up to $40 \%$, there is little evidence to support specific management protocols. ${ }^{14-8}$

The time constraints implicit in professional sport have contributed to a proliferation of injection therapies purported to enhance muscle healing and facilitate a quicker return to competition. Injections of platelet-rich plasma (PRP) are promoted by commercial entities as appropriate for muscle injury management. ${ }^{9}$

Animal studies, case reports, case series and a single-blinded randomised controlled trial have suggested a beneficial effect of PRP injections on both healing and return to play duration following muscle injury. ${ }^{10-16}$ However, a recent double-blind randomised controlled trial in amateur athletes failed to reproduce this finding, and high-quality studies in professional athletes are lacking. ${ }^{17}$

Therefore, it remains unknown if PRP therapy is effective in enhancing return to play in its primary target group of professional athletes concurrently treated with high-intensity rehabilitation in an elite athlete setting.

The Aspetar Hamstring PRP (AHP) study was designed to evaluate the efficacy of a single PRP injection in reducing the return to sport (RTS) duration among male athletes, following an acute hamstring injury.

\section{METHODS}

\section{Study design}

The AHP study was a randomised three-arm (double-blind for the two injection arms), parallel-group trial. We designed and conducted the study with the assistance of staff within Aspetar, the Qatar Orthopaedic and Sports Medicine Hospital, and received no external funding. The study protocol was approved by the Institutional Medical Ethics Board.

\section{Patient recruitment}

Patients were recruited from clubs and federations of the National Sports Medicine Program (NSMP) to which the study centre provides sports medicine services to athletes (professional, semiprofessional and amateur) of Qatar. NSMP club and federation medical staff were encouraged to contact the study coordinator directly and/or immediately refer the athlete to the study centre when an acute hamstring injury was suspected.

\section{Study patients}

To be eligible for the study, patients were required to meet the inclusion criteria of being male $18-50$ years of age, being available for regular physiotherapy and medical review, and having presented within 5 days of having suffered the acute onset of posterior thigh pain confirmed on MRI as a grade I or II hamstring lesion. ${ }^{18}$ Additional eligibility criteria are described in box 1 . The treating sports medicine physician (SMP) determined eligibility and informed the patients of the study nature. All patients provided written informed consent.

\section{Randomisation and blinding}

Eligible patients were randomised into one of three therapy groups: PRP, platelet-poor plasma (PPP) or no 


\section{Box 1 Eligibility criteria}

Inclusion criteria
Age $18-50$ years
Available for follow-up
Acute onset of posterior thigh pain
Presenting an MRI within 5 days from injury
MRI confirmed a grade I or II hamstring lesion
- Able to perform five sessions of physiotherapy a week at our
Exclusion criteria
- Contraindication to MRI
- Reinjury or chronic hamstring injury
- Unwilling to comply with follow-up
- Needle phobia
- Mverlying skin infection
- Medication with increasing bleeding risk

injection (standard physiotherapy care). Randomisation was performed in three blocks of 30 participants. To maintain the balance among the number of patients in each group, each block consisted of 30 labels (folded papers) prepared by the research coordinator evenly distributed as 10 PRP, 10 PPP and 10 no injection. Following informed consent and after blood taking, the athlete selected one folded paper which the unblinded study coordinator opened in order to provide the correct therapy to the unblinded SMP. The SMP who performed the injection was not involved in the inclusion process, or any subsequent evaluation of the patient. To ensure the concealment of group allocation, each patient received a unique research number and this number along with the identifying code was stored in a secure location for the duration of the study. The treating SMPs who assessed the outcome scores (assessor not involved in the injection procedure), physiotherapists and radiologists were blinded to the group allocation and specifically the application of any injection. Patients were not informed about the content of the injection to ensure a double-blind design for the two injection arms. All three groups underwent a standardised rehabilitation programme.

\section{Intervention}

Injection preparation

Both PRP and PPP were prepared for all athletes using the manufacturer's instructions from the GPS III centrifuge separation system (Biomet Recover, GPS III Platelet Separation System) described in detail previously. ${ }^{19}$ Briefly, in a $60 \mathrm{~mL}$ syringe, $54 \mathrm{~mL}$ of whole blood was combined with $6 \mathrm{~mL}$ of anticoagulant citrate dextrose solution (ACD-A) anticoagulant and immediately centrifuged for $15 \mathrm{~min}$ at $3200 \mathrm{rpm}$. The extraction of PRP and PPP was completed by the research coordinator following the method outlined in the commercially available separation system. No activating agent was applied to the PRP or PPP prior to injection.

\section{Injection procedure}

During the injection preparation, all patients lay prone on the surgical table facing away from the preparation area and remained in this position throughout the process. Patients allocated to the no injection group had the posterior thigh cleaned with Betadine; three dressings were placed over the area of the injury, and ice was placed on the thigh for $15 \mathrm{~min}$.

In those patients allocated to an injection (PRP or PPP), the allocated syringe with PRP or PPP was prepared and the area for injection was dressed with Betadine. Following reference to the MRI and after clinically confirming the location of the injury by palpation, the unblinded SMP infiltrated into the area of maximal tenderness corresponding to the focal region of injury on MRI. The needle was inserted into the muscle belly, to a depth anticipated to correspond to the depth of the injury on MRI. Three separate depots of $1 \mathrm{~mL}$ (either PRP or PPP) were infiltrated using a 25 -gauge needle through three injection sites into the site of the muscle injury (approximately $1 \mathrm{~cm}$ on either side of the central injection site). After the injection procedure, three dressings were placed over the injection site and the posterior thigh was iced for $15 \mathrm{~min}$.

All patients were then transferred to the physiotherapy department where rehabilitation was started within $24 \mathrm{~h}$.

\section{Standardised rehabilitation programme}

Participants underwent a daily (5 times/week) intensive, fully supervised and standardised six-stage rehabilitation programme, as described in detail previously. ${ }^{20}$ Rehabilitation was performed at the study centre by three sports physical therapists and one sports rehabilitator with 7-25 years' experience in treating elite level athletes, who were blinded to the intervention. As the effect of acute injection PRP on the time course of healing for muscle injury is unknown, functional, criteria-based progressions (as opposed to time-based progressions) were utilised for the six-stage rehabilitation protocol. The programme included range of motion exercises, progressive strengthening exercises, core stability training, agility exercises and sports-specific functional field testing (FFT).

After successfully completing the first three stages of the physiotherapy programme, the final stage of sports-specific FFT was supervised by a sports rehabilitator with 11 years of practical experience in elite sports, who was also blinded to the intervention. The programme consisted of a progression of volume and intensity drills designed to mimic the muscle fatigue and competitiveness which characterises training and game situations. Successful completion of the FFT required full unrestricted sports-specific function without any limitation and/or symptoms. Details of the rehabilitation are available in online supplementary table S1.

\section{MRI}

As previously described, patients were examined on a 1.5 Tesla Siemens Espree. ${ }^{21}$ The patients were placed in the supine position and examined using two-phased array body matrix coils strapped over the thigh and centred over the painful area, which was identified by the athlete. Axial and coronal proton density images with fat saturation (PD-FS) were obtained along the longitudinal axis of the thigh (repetition time (TR)/echo time (TE) $3490 / 27$ and a $512 \times 326$ matrix for the coronal images and TR/ TE $3000 / 32$ and a $512 \times 333$ matrix for the axial images) with one signal average each. Each MRI was assessed by one radiologist with more than 9 years of experience in musculoskeletal radiology (EA). The radiologist was blinded for the clinical status and information on whether the MRI was of the initial injury or at RTS. For assessment of the MRIs, we used standardised scoring forms based on the literature, which included the modification of Peetrons' grading; grade 0: no abnormalities; 
grade I: oedema without architectural distortion; grade II: oedema with architectural disruption; grade III: complete tear. ${ }^{18} 22$ When more than one muscle was involved, the muscle with the most extensive oedema or disruption was scored. Sites of increased T2-signal intensity were measured for the affected hamstring muscle in craniocaudal, transverse and anteroposterior dimensions on the fluid sensitive sequences (short T1 inversion recovery or PD-FS). The distances from the ischial tuberosity and longitudinal length (craniocaudal) of the lesion were recorded. In addition, the involved cross-sectional area was calculated as a percentage of the total cross-sectional area of the muscle in the transversal plane and the volume of the lesion was approximated. Excellent intratester radiologist reliability has been previously described. $^{23}$

\section{Isokinetic assessment protocol}

After completion of the rehabilitation programme, athletes underwent an isokinetic evaluation performed by the blinded physical therapists of the knee flexors and extensors (System 3, Biodex, New York, USA). Prior to testing, the athletes were instructed as to the nature and purpose of the isokinetic testing. The athletes performed a standardised warm-up procedure comprising 6 min on a stationary exercise bike (Technogym, Italy) at a resistance (in Watts) equivalent to 1.5 times their bodyweight (in $\mathrm{kg}$ ) at their chosen cadence (typically, this was approximately $85 \mathrm{rpm}$ ). ${ }^{20}$ They were then instructed to perform a minimum of a further 4 min warm-up of their choosing. Typically, this comprised dynamic running, agility drills and self-stretching. Prior to each isokinetic test, the athlete was instructed as to the mode of testing and given a minimum of three repetitions' practice, and testing was not initiated unless the athletes thought they were ready to do so. The order (ie, left, right) was randomised, and this was maintained for each of the three modes and speeds for that athlete. During the testing, vigorous verbal encouragement was provided. Testing comprised three modes and speeds. First, the athletes were tested over five repetitions at $60 \%$ s concentric knee flexion and extension (concentric quadriceps (Q conc $60^{\circ}$ ) s) $\mid$ concentric hamstrings $\left(\mathrm{H}\right.$ conc $\left.60^{\circ} / \mathrm{s}\right)$ ). This was followed by 10 repetitions at $300 \%$ s concentric knee flexion/extension (Q conc $300 \% \mathrm{~s} \mid \mathrm{H}$ conc $300 \% \mathrm{~s})$. Finally, they performed five repetitions at $60 \% \mathrm{~s} \mid 180 \% \mathrm{~s}$ eccentric knee extension/flexion (eccentric hamstrings ( $\mathrm{H} \mathrm{ecc}) \mid \mathrm{H}$ conc). Comparison (percentage of function) was made with the contralateral limb.

\section{Haematological analysis}

For immediate analysis of whole blood platelet and leucocyte concentration, blood was sampled from the antecubital vein with $10 \mathrm{~mL}$ drawn into an EDTA-coated tube. Analysis was completed using the CELL-DYN 3700 SL analyser (Coulter Count; Abbot Diagnostics, Chicago, USA). ${ }^{19}$

\section{Outcome measures}

Return to sport

The primary outcome was the time to RTS expressed as the number of days from injury (day 0) to the completion of the full rehabilitation programme and clearance for RTS by the treating SMP (blinded to the intervention). The treating SMP clinically reviewed athletes on a weekly basis and immediately on completion of the rehabilitation programme. The guidelines for making the final RTS decision included successful and asymptomatic completion of the progressive criteria-based

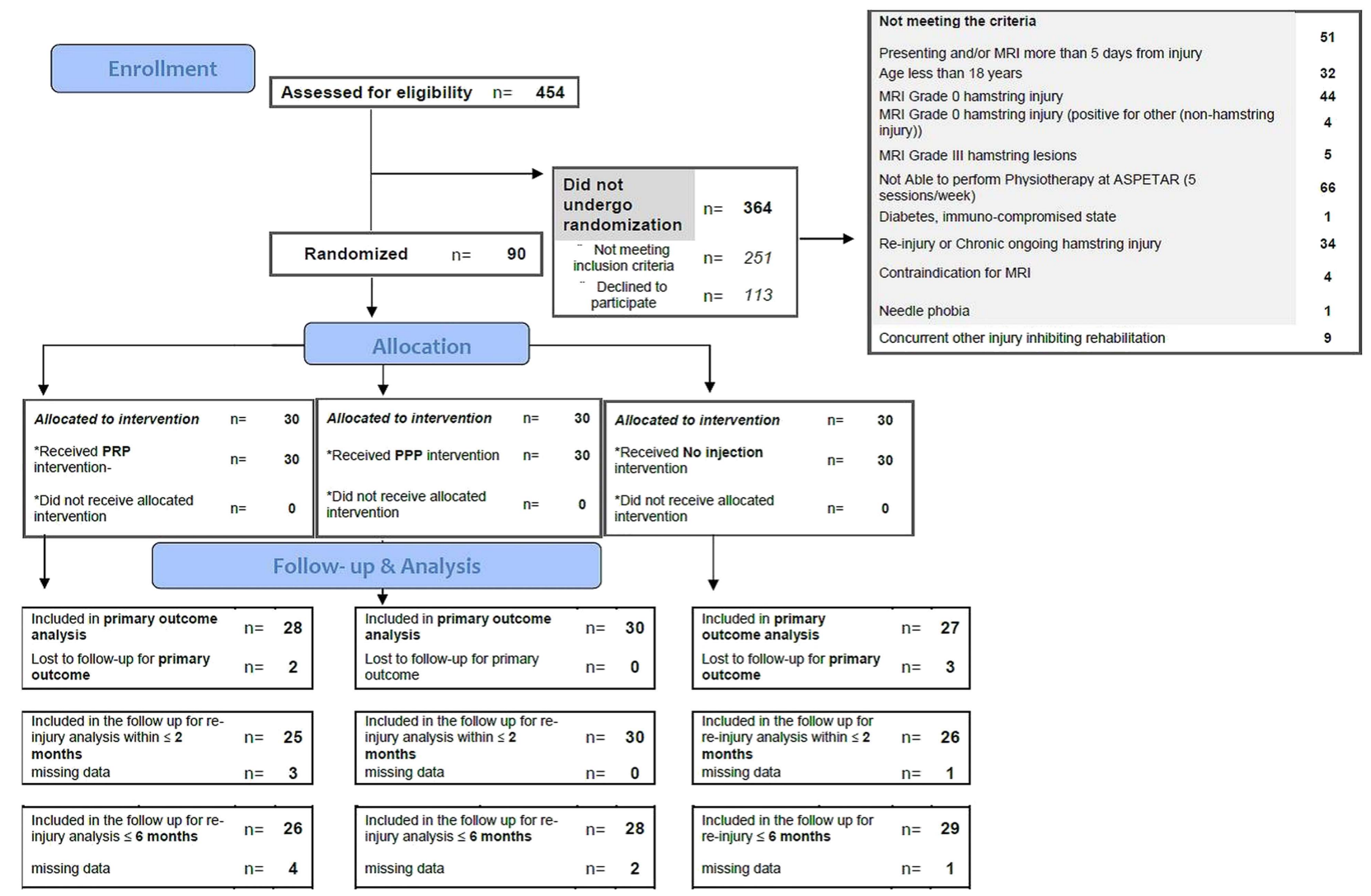

Figure 1 Methodological flow chart (PPP, platelet-poor plasma; PRP, platelet-rich plasma). 
rehabilitation programme, clinical evaluation and interpretation of the results of isokinetic assessment. ${ }^{20}$

Secondary outcome scores, compliance and adverse effects

Patients were monitored by telephone on a monthly basis for 6 months following RTS, and in the event of any clinical suspicion of reinjury, the player was advised to immediately consult the hospital and/or study coordinator. Acute hamstring strain injuries at the same site, occurring within either 2 or 6 months from RTS, were classified as reinjuries. Other secondary outcome scores included isokinetic strength testing at RTS and alteration of T2-signal intensity on MRI at 3 weeks follow-up compared with the baseline MRI assessments. Both assessments have been described in detail previously. ${ }^{20} 23$

Adverse effects were recorded during the weekly clinical follow-up with the treating SMP and at the final telephone

Table 1 Baseline characteristics of patients*

\begin{tabular}{|c|c|c|c|}
\hline & $\begin{array}{l}\text { Platelet-rich plasma group } \\
(\mathrm{n}=30)\end{array}$ & $\begin{array}{l}\text { Platelet-poor plasma group } \\
(n=30)\end{array}$ & $\begin{array}{l}\text { No injection group } \\
(n=30)\end{array}$ \\
\hline Age (years) & $\begin{array}{l}26.6 \pm 5.9 \\
26.3(21.2-31.4)\end{array}$ & $\begin{array}{l}25.6 \pm 5.8 \\
24.9(22.1-29.3)\end{array}$ & $\begin{array}{l}25.5 \pm 5.7 \\
24.3(20.7-29.4)\end{array}$ \\
\hline Male gender & $30(100.0)$ & $30(100.0)$ & $30(100.0)$ \\
\hline \multicolumn{4}{|l|}{ Sports category } \\
\hline Athletics & $0(0.0)$ & $2(6.7)$ & $2(6.7)$ \\
\hline Basketball & $1(3.3)$ & $1(3.3)$ & $0(0.0)$ \\
\hline Decathlon & $1(3.3)$ & $0(0.0)$ & $0(0.0)$ \\
\hline Football & $22(73.3)$ & $22(73.3)$ & $22(73.3)$ \\
\hline Futsal & $3(10.0)$ & $3(10.0)$ & $2(6.7)$ \\
\hline Handball & $1(3.3)$ & $1(3.3)$ & $1(3.3)$ \\
\hline Hockey & $1(3.3)$ & $0(0.0)$ & $1(3.3)$ \\
\hline Physical coach football & $0(0.0)$ & $0(0.0)$ & $1(3.3)$ \\
\hline Squash & $0(0.0)$ & $1(3.3)$ & $0(0.0)$ \\
\hline Volleyball & $0(0.0)$ & $0(0.0)$ & $1(3.3)$ \\
\hline Weightlifting and bodybuilding & $1(3.3)$ & $0(0.0)$ & $0(0.0)$ \\
\hline \multicolumn{4}{|l|}{ Level of sports } \\
\hline Professional & $30(100)$ & $28(93.3)$ & $29(96.7)$ \\
\hline Competitive & $0(0)$ & $2(6.7)$ & $1(3.3)$ \\
\hline Sprinting type of injury & $14(46.7)$ & $20(66.7)$ & $22(73.3)$ \\
\hline Previous hamstring injuries & $19(63.3)$ & $15(50.0)$ & $15(50.0)$ \\
\hline Previous ipsilateral hamstring injuries & $10(33.3)$ & $10(33.3)$ & $8(26.7)$ \\
\hline Maximum pain score with the injury & $\begin{array}{l}6.8 \pm 2.2 \\
7(5.0-8.0)\end{array}$ & $\begin{array}{l}6.6 \pm 1.8 \\
7(5.0-8.0)\end{array}$ & $\begin{array}{l}6.9 \pm 1.7 \\
7(6.0-8.0)\end{array}$ \\
\hline Length of the pain palpation $(\mathrm{cm})$ & $\begin{array}{l}6.7 \pm 3.7 \\
5(4.0-9.5)\end{array}$ & $\begin{array}{l}7.6 \pm 3.9 \\
7.75(4.5-10.0)\end{array}$ & $\begin{array}{l}6.5 \pm 3.3 \\
6(4.0-8.0)\end{array}$ \\
\hline Width of the pain palpation $(\mathrm{cm})$ & $\begin{array}{l}3.4 \pm 1.7 \\
3(2.0-4.5)\end{array}$ & $\begin{array}{l}4.4 \pm 2.9 \\
3.5(3.0-6.0)\end{array}$ & $\begin{array}{l}3.7 \pm 1.9 \\
3.5(2.5-4.5)\end{array}$ \\
\hline No full knee extension deficit at rest & $2(6.7)$ & $1(3.3)$ & $0(0.0)$ \\
\hline Painful passive straight leg raise (yes only) & $30(100.0)$ & $29(96.7)$ & $25(83.3)$ \\
\hline Days between injury and intervention (days) & $\begin{array}{l}1.8 \pm 0.9 \\
2(1.0-3.0)\end{array}$ & $\begin{array}{l}1.8 \pm 1.1 \\
1(1.0-3.0)\end{array}$ & $\begin{array}{l}2.3 \pm 1.1 \\
2(1.0-3.0)\end{array}$ \\
\hline \multicolumn{4}{|l|}{ MRI characteristics of oedema } \\
\hline Anteroposterior $(\mathrm{cm})$ & $\begin{array}{l}2.3 \pm 1.4 \\
2(1.4-2.9)\end{array}$ & $\begin{array}{l}2.5 \pm 1.5 \\
2.2(1.4-3.0)\end{array}$ & $\begin{array}{l}2.7 \pm 1.7 \\
2.25(1.2-4.1)\end{array}$ \\
\hline Anteroposterior (\%) & $\begin{array}{l}43.0 \pm 25.0 \\
36(24.0-52.0)\end{array}$ & $\begin{array}{l}41.0 \pm 25.0 \\
38(26.0-51.0)\end{array}$ & $\begin{array}{l}46.0 \pm 28.0 \\
41(22.0-66.0)\end{array}$ \\
\hline Mediolateral $(\mathrm{cm})$ & $\begin{array}{l}2.4 \pm 1.3 \\
2.4(1.2-3.2)\end{array}$ & $\begin{array}{l}2.1 \pm 1.2 \\
1.8(1.4-2.8)\end{array}$ & $\begin{array}{l}2.3 \pm 1.3 \\
2.4(1.1-3.3)\end{array}$ \\
\hline Mediolateral (\%) & $\begin{array}{l}53.0 \pm 28.0 \\
47(29.0-73.0)\end{array}$ & $\begin{array}{l}48.0 \pm 24.0 \\
43(31.0-69.0)\end{array}$ & $\begin{array}{l}50.0 \pm 24.0 \\
51(31.0-63.0)\end{array}$ \\
\hline Craniocaudal (cm) & $\begin{array}{l}15.8 \pm 8.2 \\
14.05(9.1-23.0)\end{array}$ & $\begin{array}{l}14.6 \pm 7.4 \\
14.4(9.2-20.2)\end{array}$ & $\begin{array}{l}15.5 \pm 6.1 \\
15.8(10.6-20.0)\end{array}$ \\
\hline Volume $\left(\mathrm{cm}^{3}\right)$ & $\begin{array}{l}77.6 \pm 108.5 \\
29.21(9.9-82.0)\end{array}$ & $\begin{array}{l}61.9 \pm 83.4 \\
33.41(7.4-64.6)\end{array}$ & $\begin{array}{l}75.8 \pm 74.6 \\
62.83(10.0-135.7)\end{array}$ \\
\hline Cross-sectional area (\%) & $\begin{array}{l}28.0 \pm 28.0 \\
17(8.0-39.0)\end{array}$ & $\begin{array}{l}24.0 \pm 23.0 \\
15(8.0-33.0)\end{array}$ & $\begin{array}{l}29.0 \pm 24.0 \\
23(9.0-51.0)\end{array}$ \\
\hline Distance from most caudal ischial tuberosity $(\mathrm{cm})$ & $\begin{array}{l}9.6 \pm 7.7 \\
9.4(2.3-16.6)\end{array}$ & $\begin{array}{l}12.0 \pm 8.3 \\
11.9(3.3-19.5)\end{array}$ & $\begin{array}{l}9.5 \pm 7.0 \\
8.7(4.5-13.0)\end{array}$ \\
\hline Grade I & $17(56.7)$ & $16(55.2)$ & $13(43.3)$ \\
\hline Grade II & $13(43.3)$ & $13(44.8)$ & $17(56.7)$ \\
\hline
\end{tabular}

*Data are either shown as mean \pm SD and median (IQR) for continuous variables or frequency and valid column percentage (\%) for categorical variables. 
follow-up. Sports physical therapists were instructed to report adverse effects that influenced the rehabilitation programme. Daily adherence to the rehabilitation programme was recorded by the treating physical therapist.

Power and statistical analysis

On the basis of previous studies, our alternative hypothesis was that in the group of patients who received PRP injection (active comparator), the RTS would be 25\% (6.75 days; practical implication would be 1 week) quicker in comparison with the PPP (placebo comparator) and/or no injection group (usual care/no intervention). The SD was estimated at 8.75 days. ${ }^{24} 25$

We calculated that a sample of 30 was required in each group to detect this difference, with a power of $80 \%$ with two-sided testing at a significance of 0.05 , and assuming that $10 \%$ would be lost to follow-up.

All randomised patients received the allocated intervention. All statistical analyses were performed with SPSS V.21.0 software. To determine if the variables of interest were balanced between the randomised arms, we performed Pearson $\chi^{2}$ test or exact tests for categorical data and one-way analysis of variance between the three groups for continuous data. Where there was deviation from normality, non-parametric equivalent Kruskal-Wallis tests were used. For the primary end point (RTS in days), Kaplan-Meier curves with cumulative survival curves in three groups were plotted. To determine the treatment effect of intervention on the time to RTS, a Cox proportional-hazards model and a generalised linear model were performed to compute hazard ratios (HR) and mean RTS, respectively. Adjustments were made for baseline variables that influenced the primary outcome with $\mathrm{p}<0.10$. Patients sustaining a nonhamstring injury before RTS, which was assumed to be unrelated to the injection intervention, were censored in the analysis at the time of this injury (non-informative censoring). The assumption of proportional hazard for three treatment groups was met. Patients lost to follow-up before RTS were censored at the time of the last available follow-up. All primary analyses performed were based on the intention-to-treat principle. In addition, we performed imputation analysis on the missing data on RTS and the sensitivity analysis showed no difference from the initial analysis.

\section{RESULTS}

\section{Study patients and follow-up}

From November 2009 to October 2013, 357 athletes were screened for eligibility and a total of 90 athletes were randomly assigned to one of the three groups (figure 1). The baseline characteristics are shown in table 1 . For the primary outcome, analysis adjustments were made for the baseline variables maximum pain score and MRI volume of oedema. Five patients (2 patients in the PRP group and 3 in the no injection group) were lost to follow-up before RTS and were censored at the latest follow-up for the primary outcome (see online supplementary table S2). Seven of the 90 patients had data on reinjury missing at 6 months follow-up (see online supplementary table S3). Nineteen SMPs were involved in the allocation process and nine SMPs in the injection procedure; all had 7-22 years' experience in working with elite and recreational athletes.

\section{Primary outcome: time to RTS}

The median duration of RTS was 21 days (95\% CI 17.9 to 24.1 ) in the PRP group, 27 days (95\% CI 20.6 to 33.4) in the PPP group and 25 days (95\% CI 21.5 to 28.5 ) in the no injection group (figure 2). On the basis of Cox regression, the

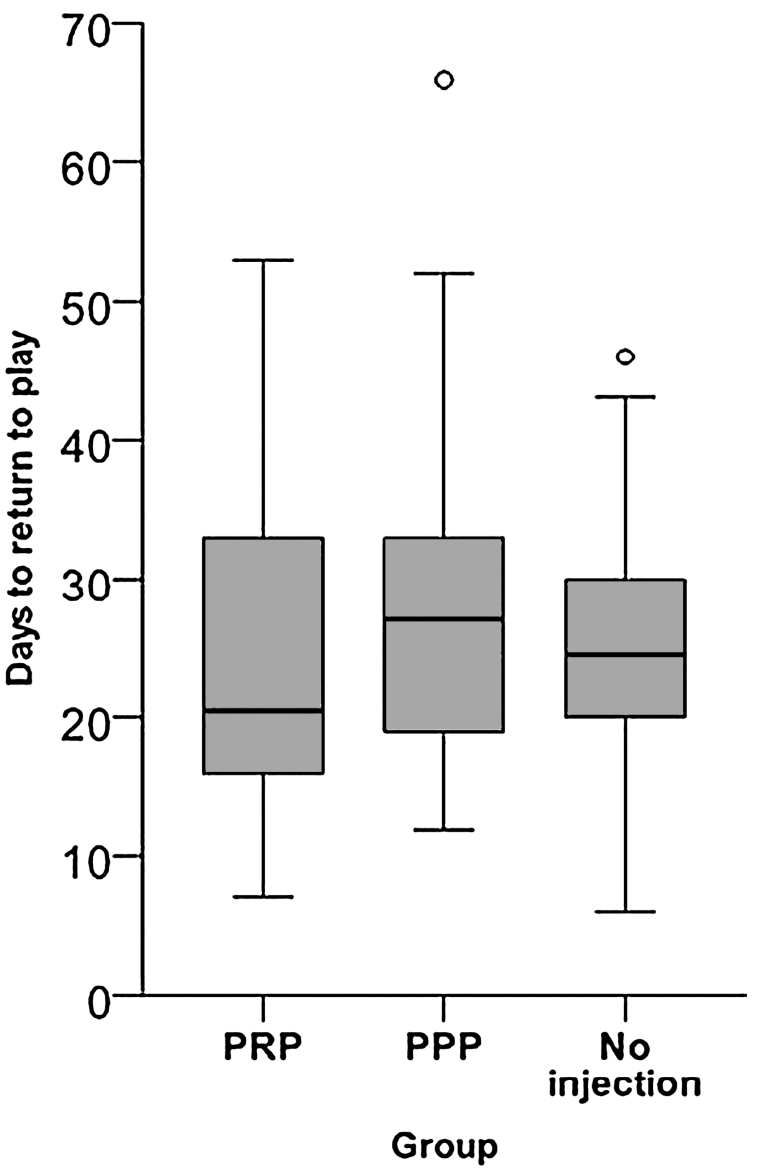

Figure 2 Box plot showing median and IQR for number of days to return to play in the three groups. Closed circles represent individual outliers (PPP, platelet-poor plasma; PRP, platelet-rich plasma).

adjusted HR for the PRP group compared with the PPP group was 2.29 (95\% CI 1.30 to 4.04) $\mathrm{p}=0.004$; for the PRP group compared with the no injection group, 1.48 (95\% CI 0.869 to 2.520) $\mathrm{p}=0.15$, and for the PPP group compared with the no injection group 1.57 (95\% CI 0.88 to -2.80$) \mathrm{p}=0.13$ (figure 3). This HR may be interpreted as meaning that at any given point in time, a patient infiltrated with PRP has a 2.29 times greater chance of return to play compared with a patient given PPP.

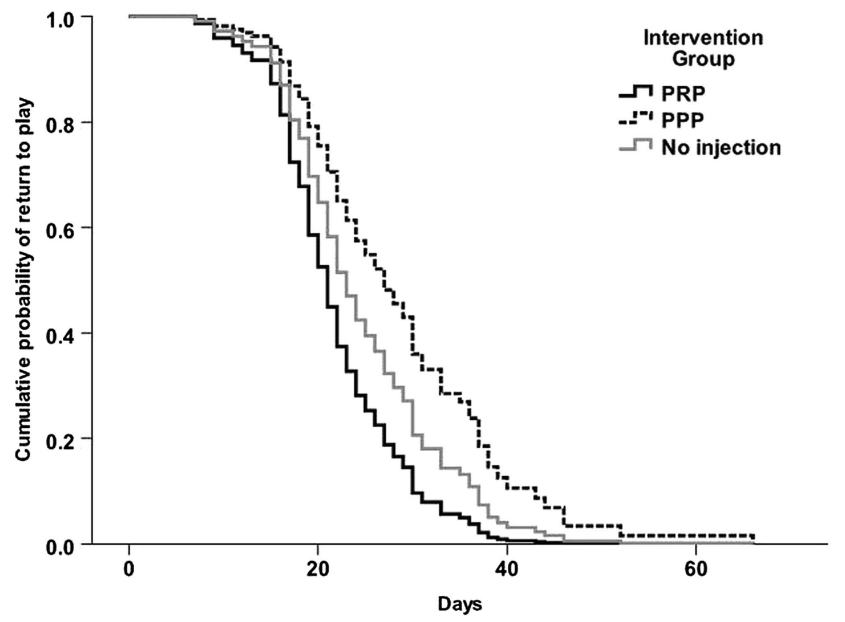

Figure 3 Kaplan-Meier curves showing the cumulative incidence of return to play (PPP, platelet-poor plasma; PRP, platelet-rich plasma). 
Table 2 Cumulative reinjury at 2 and 6 months after return to sport

\begin{tabular}{|c|c|c|c|c|c|c|}
\hline & \multicolumn{3}{|l|}{2 months } & \multicolumn{3}{|l|}{6 months } \\
\hline & $\begin{array}{l}\text { Platelet-rich plasma } \\
(n=25)\end{array}$ & $\begin{array}{l}\text { Platelet-poor plasma } \\
(n=30)\end{array}$ & $\begin{array}{l}\text { No intervention } \\
(n=26)\end{array}$ & $\begin{array}{l}\text { Platelet-rich plasma } \\
(n=26)\end{array}$ & $\begin{array}{l}\text { Platelet-poor plasma } \\
(\mathrm{n}=28)\end{array}$ & $\begin{array}{l}\text { No intervention } \\
(n=29)\end{array}$ \\
\hline Reinjury number (\%) & $2(8.0 \%)$ & $2(6.7 \%)$ & $2(7.7 \%)$ & $2(7.7 \%)$ & $3(10.7 \%)$ & $3(10.3 \%)$ \\
\hline
\end{tabular}

The generalised linear model showed that the adjusted difference for time to RTS between the PRP and PPP groups was -5.7 days $(95 \%$ CI -10.1 to -1.4$) \mathrm{p}=0.01$; between the PRP and no injection groups, it was -2.9 days $(95 \% \mathrm{CI}-7.2$ to 1.4$)$ $\mathrm{p}=0.189$, and between the PPP and no injection groups it was 2.8 days $(95 \% \mathrm{CI}-1.6$ to 7.2$) \mathrm{p}=0.210$.

\section{Secondary outcome measures}

Reinjuries within 6 months occurred in 2 of the 26 patients $(7.7 \%)$ of the PRP group, in 3 of the 28 patients $(10.7 \%)$ of the PPP group and in 3 of the 29 patients $(10.3 \%)$ of the no injection group (table 2). There was no significant difference in the reinjury rate at either 2 months $(p=0.999)$ or 6 months $(p=0.905)$ between the study groups. The odds of reinjury within 2 months in the PPP group were OR $=0.82195 \% \mathrm{CI}$ (0.107 to 6.293) $\mathrm{p}=0.850$ compared with the PRP group; the odds of reinjury within 2 months in the no injection group were $\mathrm{OR}=0.958$ (95\% CI 0.124 to 7.383$) \mathrm{p}=0.967$ compared with the PRP group. The 6 month odds of reinjury in the PPP group were $\mathrm{OR}=1.44$ (0.221 to 9.388) $\mathrm{p}=0.703$ compared with the PRP group; the odds of reinjury within 6 months in the no injection group were $\mathrm{OR}=1.385$ (95\% CI 0.213 to 9.013), $\mathrm{p}=0.733$ compared with the PRP group.

There were no significant between-group differences for the secondary outcome scores of isokinetic strength testing and MRI alterations in signal intensity (tables 3 and 4).

\section{Adherence to the rehabilitation programme}

The median adherence to the scheduled rehabilitation sessions was $85.5 \%$ (IQR 75.0-100.0\%) in the PRP group, 92.3\% (IQR $84.8-100 \%$ ) in the PPP group and $87.5 \%$ (IQR 68.7-86.7\%) in the no injection group. There were no significant differences in adherence to the rehabilitation programme between the study groups $(\mathrm{p}=0.234)$.

\section{Whole blood, PRP and PPP analysis}

Compared with the whole blood platelet concentration increased by a factor or 3.2 in PRP and decreased by a factor 8.5 in the PPP (table 5).

\section{Adverse events}

There were no serious adverse events reported.

\section{DISCUSSION}

In our randomised controlled trial involving predominantly professional football athletes suffering an acute hamstring injury, we found that a single PRP injection in combination with an intensive rehabilitation programme did not reduce the RTS duration when compared with rehabilitation only. In contrast, a single PRP injection in combination with intensive rehabilitation reduced the RTS duration when compared with a single PPP injection and rehabilitation.

This study has some strengths and limitations. A strength is that predominantly professional athletes undergoing a daily intensive rehabilitation programme were included, as these are currently the primary target group for PRP injections. Moreover, with our single-centre rehabilitation programme in an elite athlete medical setting with rehabilitation supervision by three highly experienced sports physical therapists, we were able to control the content, utilisation and daily compliance with the rehabilitation programme, resulting in a quick RTS and a relatively low reinjury rate. Our standardised imaging, assessment and follow-up regimen with blinded sports physicians ensured a comprehensive approach to injury management and data collection. The double-blind design of the two injection arms minimised the risk of bias and our imputation and sensitivity analysis showed robustness of results. All attempts were made to ensure blinding of the therapist to injection or no injection, but this cannot be completely guaranteed, and it was not monitored if there was information revealed by the patient to the therapist. Therapists did not actively seek this information. As the treating physical therapist was responsible for the decision to progress through the six-phase criteria-based rehabilitation process, there is a risk of bias when comparing with the no injection group. With the objective criteria-based progression criteria, we have tried to minimise this potential bias. Our study patients were predominantly male professional football players, which may limit generalisability to other athletes. Furthermore, where the area of injury was determined by reference to the ultrasound

Table 3 Percentage difference in isokinetic strength assessment at return to sport in the injured compared with the uninjured leg

\begin{tabular}{|c|c|c|c|c|c|c|}
\hline & \multicolumn{2}{|c|}{$\begin{array}{l}\text { Platelet-rich plasma } \\
\mathrm{n}=24\end{array}$} & \multicolumn{2}{|c|}{$\begin{array}{l}\text { Platelet-poor plasma } \\
n=29\end{array}$} & \multicolumn{2}{|c|}{$\begin{array}{l}\text { No injection } \\
n=26\end{array}$} \\
\hline & Mean \pm SD & $95 \% \mathrm{Cl}$ & Mean \pm SD & $95 \% \mathrm{Cl}$ & Mean \pm SD & $95 \% \mathrm{Cl}$ \\
\hline $\mathrm{Q}$ conc $60 \%$ s $(\%)$ & $0.7 \pm 13.7$ & -5.1 to 6.5 & $-3.8 \pm 17.9$ & -10.6 to 3.0 & $-6.6 \pm 17.4$ & -13.7 to 0.4 \\
\hline $\mathrm{H}$ conc $60 \% \mathrm{~s}(\%)$ & $-6.8 \pm 13.2$ & -12.4 to -1.2 & $-7.1 \pm 12.6$ & -11.8 to -2.3 & $-9.2 \pm 16.0$ & -15.7 to -2.8 \\
\hline $\mathrm{Q}$ conc $300 \%$ s $(\%)$ & $-0.9 \pm 14.0$ & -6.8 to 5.1 & $-1.9 \pm 17.8$ & -8.8 to 5.1 & $-3.1 \pm 14.3$ & -8.9 to 2.6 \\
\hline $\mathrm{H}$ conc $300 \%$ s (\%) & $0.5 \pm 12.5$ & -4.7 to 5.8 & $3.7 \pm 18.7^{*}$ & -3.6 to 10.9 & $-5.8 \pm 18.4$ & -13.2 to 1.6 \\
\hline $\mathrm{H}$ ecc $60 \% / \mathrm{s}(\%)$ & $-5.2 \pm 18.7$ & -13.5 to 3.1 & $-7.9 \pm 14.4^{*} \dagger$ & -13.6 to -2.2 & $2.5 \pm 17.1$ & -4.8 to 9.7 \\
\hline
\end{tabular}


Table 4 Percentage decrease (mean \pm SD and median (IQR)) in oedema on MRI at follow-up, compared with the baseline measurements*

\begin{tabular}{|c|c|c|c|c|c|c|}
\hline & \multicolumn{2}{|c|}{$\begin{array}{l}\text { Platelet-rich plasma } \\
n=26\end{array}$} & \multicolumn{2}{|c|}{$\begin{array}{l}\text { Platelet-poor plasma } \\
\mathrm{n}=27\end{array}$} & \multicolumn{2}{|c|}{$\begin{array}{l}\text { No injection } \\
n=26\end{array}$} \\
\hline & Mean \pm SD & Median (IQR) & Mean \pm SD & Median (IQR) & Mean \pm SD & Median (IQR) \\
\hline Delay in dayst & $9.7 \pm 16.7$ & $4(1-13)$ & $7.6 \pm 9.6$ & $5(2-9)$ & $12.5 \pm 18.4$ & $7(3-14)$ \\
\hline Craniocaudal (cm) & $35.4 \pm 60.5$ & $41(15-65)$ & $18.5 \pm 107.6$ & $41(13-72)$ & $42.7 \pm 47.5$ & $54(23-69)$ \\
\hline Anteroposterior $(\mathrm{cm})$ & $35.1 \pm 62.0$ & $48(15-64)$ & $10.7 \pm 108.1$ & $36(12-66)$ & $38.7 \pm 50.0$ & $52(12-66)$ \\
\hline Mediolateral (cm) & $45.2 \pm 37.4$ & $43(13-67)$ & $14.9 \pm 73.2$ & $43(-6-58)$ & $39.2 \pm 37.2$ & $34(20-69)$ \\
\hline Volume $\left(\mathrm{cm}^{3}\right)$ & $62.1 \pm 66.4$ & $81(59-93)$ & $9.6 \pm 217.6$ & $84(56-91)$ & $63.5 \pm 64.2$ & 78 (58-94) \\
\hline Cross-sectional area (\%) & $46.8 \pm 74.7$ & $69(21-87)$ & $-10.4 \pm 206.1$ & $70(15-83)$ & $49.0 \pm 68.8$ & $71(35-86)$ \\
\hline
\end{tabular}

*No statistical significance was found between the three groups.

tAs per protocol, MRI was planned at third week postinjury. Number of days delayed in MRI is presented.

and MRI examinations and confirmed with palpation, our injection protocol did not include standardised ultrasonographic guidance, which may have influenced the accuracy of the injection technique. The optimal location for any injection is not known, and our injection technique allows for a pragmatic and generalised distribution of the injectate to the area of injury. Similarly, while not observed by Reurink et al, ${ }^{17}$ the sequential application of further PRP or PPP injections could potentially result in a different outcome. This question was beyond the scope of this research to evaluate.

Two recently published randomised controlled trials evaluated the efficacy of PRP injections in acute hamstring injuries in a non-professional setting. In a double-blind RCT involving 80 non-professional athletes, Reurink et $a l^{17}$ found no benefit of PRP compared with saline injection when both were combined with a mixed home and clinic-based rehabilitation programme. In contrast, a single-blinded RCT with a smaller sample size found that PRP injection in combination with a home-based rehabilitation programme significantly reduced the RTS duration in non-professional athletes. ${ }^{16}$ In the latter study, unblinded patients, caregivers and the absence of a placebo injection may have introduced bias. While Reurink used saline as a placebo, the present study used PPP. Since the alleged benefits of PRP are suggested to be the result of elevated concentrations of growth factors (GF), PPP was chosen as a placebo in this study due to the reduced platelet count and growth factor concentrations relative to PRP. Both groups still received both an injection and a fluid bolus in the area of the injury. That the PRP injection resulted in a reduced RTS duration when compared with PPP suggests a physiological distinction between the two injectates.

Table 5 Platelets, leucocytes and RBCs $\left(\times 10^{9} / \mathrm{L}\right)$ in whole blood, PRP or PPP (for groups injected)*

\begin{tabular}{ccccc}
\hline & $\begin{array}{l}\text { PRP } \\
\mathbf{n}=\mathbf{3 0}\end{array}$ & $\begin{array}{l}\text { PPP } \\
\mathbf{n}=\mathbf{3 0}\end{array}$ & $\begin{array}{l}\text { No injection } \\
\mathbf{n}=\mathbf{3 0}\end{array}$ & $\mathbf{p}$ Value \\
\hline Whole blood & & & & \\
$\quad$ Platelets & $237.2 \pm 50.2$ & $256.2 \pm 57.1$ & $247.9 \pm 40.9$ & 0.338 \\
Leucocytes & $5.9 \pm 2.2$ & $6.0 \pm 1.5$ & $5.7 \pm 1.5$ & $0.730 \dagger$ \\
RBC count & $5.2 \pm 0.4$ & $5.2 \pm 0.4$ & $5.3 \pm 0.4$ & 0.245 \\
Injection & & & & \\
Platelets & $765.8 \pm 423.6$ & $30.3 \pm 23.0$ & NA & \\
Leucocytes & $26.1 \pm 13.7$ & $0.03 \pm 0.03$ & NA & \\
RBC count & $1.0 \pm 0.9$ & $0.001 \pm 0.001$ & NA & \\
\hline
\end{tabular}

*Plus-minus values are mean \pm SD.

tp Value calculated based on a non-parametric test.

NA, not applicable; PPP, platelet-poor plasma; PRP, platelet-rich plasma; RBC, red blood cell.
The RTS duration achieved in this study is comparable to that seen in previous studies involving professional athletes $22 \quad 26 \quad 27$ but faster than that seen in recreational athletes. ${ }^{17}$ Hamid et $a l^{16}$ reviewed their athletes weekly and found an RTS of 42 days for the control group and 26 days for the PRP injection. In contrast to the RCT involving recreational athletes, ${ }^{16}{ }^{17}$ in this study athletes participated in a daily (5 days/week) highintensity rehabilitation programme with a high level of compliance. In this study, the RTS duration for the PRP, PPP and physiotherapy only (no injection) groups compare favourably with both these studies. Furthermore, the observed reinjury rate $(8 \%)$ at 2 months is lower than previously reported in professional European football players $(16 \%)^{1}$ and in the study population of Reurink et $a l^{17}(16 \%)$, suggesting an effective rehabilitation and RTS protocol. Taken together, these findings suggest that intensive rehabilitation is a critical element in a successful RTS.

While the current blinded study design with two injection arms was comparable to that of Reurink et al, ${ }^{17}$ our observed difference between PRP and PPP is in contrast to the lack of difference observed between PRP and saline injection. Advocates of PRP may argue that our detected difference between PRP and PPP was due to the positive regenerative effect of PRP, while others might propose a negative effect of PPP. In the absence of any difference between either PRP or PPP compared with no injection, this question remains unresolved. Our findings indicate that there is no benefit, in regard to either RTS duration or reinjury risk, of adding a single PRP injection to the intensive rehabilitation of professional (predominantly football) athletes with a grade I or II hamstring injury. PPP may result in a slightly slower RTS than PRP when both are combined with rehabilitation.

There remain many unanswered questions when considering the use of PRP for muscle injuries in athletes. While this study fails to show any benefit of a single injection of PRP, it remains

\section{What are the new findings?}

- Our findings indicate that there is no benefit of a single platelet-rich plasma (PRP) injection over intensive rehabilitation in professional athletes who have sustained acute, MRI positive hamstring injuries.

- A single PRP injection in combination with intensive rehabilitation reduced the return to sport duration when compared with a single platelet-poor plasma injection and rehabilitation. 
How might it impact on clinical practice in the near future?

- Intensive physiotherapy led rehabilitation remains the primary means of ensuring an optimal return to sport following muscle injury.

- Single injections of platelet-rich plasma are not indicated in professional athletes who have sustained acute, MRI-positive hamstring injuries.

a possibility that further injections, or injections delivered at a different time period or location, may have had some impact. Furthermore, there is a known variation in the white cell and red cell concentrations in different PRP formulations, which could potentially impact on the outcome. All of these elements require further evaluation before PRP can be routinely recommended for use in acute muscle strain injuries. In the interim, intensive physiotherapy led rehabilitation remains the primary means of ensuring an optimal RTS following muscle injury.

Collaborators The Aspetar Hamstring PRP (AHP) study group: Dr Mohammed Ghanem, Dr Khalifa Alkuwari, Director General Aspetar Orthopaedic and Sports Medicine Hospital; Dr Justin Paoloni, Dr Claude Tremblay, Dr Massimiliano Sala, Dr Eduardo Mauri, Dr Celeste Geertsema, Dr Robbart van Linschoten, Dr Aston Ngai, Dr Stephen Targett, Dr Adam Weir, Dr Frank van Hellmondt, Dr Liesel Geertsema, Dr Massimo Manara, Dr Paul Dijkstra, Dr Juan Manuel Alonso, Dr. York Schumacher; Riadh Miladi, Philipp Jacobsen, Patrice Muxart, Roald Otten, Mohsen Abassi, Polyvios Kyritsis; Justin Grantham, Wade Knez, Faten Smiley, Arnlaug Wangensteen, Andreas Serner, Rima Tabanji; Dr Nabil Jomaah, Dr Bernard Roger, Clubs and federations of the National Sports Medicine Program (NSMP); Al Ahli Sports Club, Al Arabi Sports club, Al Gharafa Sports Club, Al jaish team, Al kharitiyath Sports Club, Al Khor Sports Club, Al Markhiya Sports Club, Al Rayyan Sports Club, Al Sadd Sports Club, Al Sailiya Sports Club, Al Shahaniya Sports Club, Al Shamal Sports Club, Al Wakrah Sports Club, Mesaimeer Sports Club, Military Sports Association, Moaither Sports Club, Lakhwaya Sports Club, Qatar Hockey Federation, Qatar Sports Club, Qatar Armed Forces, Qatar Basketball Federation, Qatar Football Association, Qatar Taekwondo \& Karate Federation, Qatar Weightlifting and Bodybuilding Federation, Qatar National team, Um Salal Sports Club, Ziyad R Mahfoudour, Weil Cornell Medical College Qatar.

Contributors $\mathrm{BH}$ contributed in the concept and design of the study, acquisition and interpretation of the data, and in drafting and revising of the manuscript. JLT was involved in the acquisition and interpretation of the data, and in drafting and revising of the manuscript. EA and RW participated in the acquisition and interpretation of the data, and in revising of the manuscript. SB participated in the acquisition of the data, and in drafting and revising of the manuscript. CE contributed in the concept of the study, acquisition and interpretation of the data, and in revising of the manuscript. AF contributed in the design of the study, interpretation of the data, and in drafting and revising of the manuscript. $\mathrm{HC}$ contributed in the concept and design of the study, acquisition and interpretation of the data, and in revising of the manuscript. All the authors gave their approval for the final version of the manuscript.

Funding Internally funded by Aspetar; Qatar Orthopaedic and Sports Medicine Hospital.

Competing interests None declared.

Ethics approval The study protocol was approved by the Institutional Medical Ethics Board of Aspetar/Aspire Zone.

Provenance and peer review Not commissioned; externally peer reviewed.

Data sharing statement Patient level data and/or full data set and/or technical appendix and/or statistical code are available from the corresponding author at bruce.hamilton@hpsnz.org.nz.

Open Access This is an Open Access article distributed in accordance with the Creative Commons Attribution Non Commercial (CC BY-NC 4.0) license, which permits others to distribute, remix, adapt, build upon this work non-commercially, and license their derivative works on different terms, provided the original work is properly cited and the use is non-commercial. See: http://creativecommons.org/ licenses/by-nc/4.0/

\section{REFERENCES}

1 Ekstrand J, Hagglund M, Walden M. Epidemiology of muscle injuries in professional football (soccer). Am J Sports Med 2011;39:1226-32.

2 Orchard J, Seward H. Epidemiology of injuries in the Australian Football League, seasons 1997-2000. Br J Sports Med 2002;36:39-44.

3 Feeley BT, Kennelly S, Barnes R, et al. Epidemiology of National Football League training camp injuries from 1998 to 2007. Am I Sports Med 2008;36:1597-603.

4 Hamilton B. Hamstring muscle strain injuries: what can we learn from history? $\mathrm{Br} J$ Sports Med 2012;46:900-3.

5 Verrall GM, Slavotinek JP, Barnes PG, et al. Assessment of physical examination and magnetic resonance imaging findings of hamstring injury as predictors for recurrent injury. J Orthop Sports Phys Ther 2006;36:215-24.

6 Ekstrand J, Hagglund M, Walden M. Injury incidence and injury patterns in professional football: the UEFA injury study. Br J Sports Med 2011:45:553-8.

7 Eirale C, Farroq A, Smiley FA, et al. Epidemiology of football injuries in Asia: a prospective study in Qatar. J Sci Med Sport 2013;16:113-17.

8 Orchard J. The management of muscle strain injuries: an early return versus the risk of recurrence. Clin I Sport Med 2002;12:3-5.

9 Maffulli N. Autologous blood products in musculoskeletal medicine. BMJ 2013;346: f2979.

10 Hamilton B, Knez W, Eirale $C$, et al. Platelet enriched plasma for acute muscle injury. Acta Orthopaedica Belgica 2010;76:443-8.

11 Hammond J, Hinton RY, Curl LA, et al. Use of autologous platelet-rich plasma to treat muscle strain injuries. Am J Sports Med 2009;37:1135-42.

12 Loo W, Lee $D$, Soon M. Plasma rich in growth factors to treat adductor longus tear. Ann Acad Med 2009;38:733-4.

13 Rettig AC, Meyer S, Bhadra A. Platelet-rich plasma in addition to rehabilitation for acute hamstring injuries in NFL players. Orthop J Sports Med 2013;1:1-5.

14 Wright-Carpenter T, Klein $\mathrm{P}$, Schaferhoff $\mathrm{P}$, et al. Treatment of muscle injuries by local administration of autologous conditioned serum: a pilot study on sportsmen with muscle strains. Int I Sports Med 2004;25:588-93.

15 Wright-Carpenter T, Opolon P, Appell HJ, et al. Treatment of muscle injuries by local administration of autologous conditioned serum: animal experiments using a muscle contusion model. Int I Sports Med 2004;25:582-7.

16 Hamid MS, Mohamed Ali MR, Yusof A, et al. Platelet-rich plasma injections for the treatment of hamstring injuries: a randomized controlled trial. Am I Sports Med 2014:42:2410-18.

17 Reurink G, Goudswaard GJ, Moen MH, et al. Platelet-rich plasma injections in acute muscle injury. N Engl J Med 2014;370:2546-7.

18 Peetrons P. Ultrasound of muscles. Eur Radiol 2002;12:35-43.

19 Hamilton B, Tol JL, Knez W, et al. Exercise and the platelet activator calcium chloride both influence the growth factor content of platelet-rich plasma (PRP): overlooked biochemical factors that could influence PRP treatment. Br I Sports Med 2015;49:956-9.

20 Tol JL, Hamilton B, Eirale C, et al. At return to play following hamstring injury the majority of professional football players have residual isokinetic deficits. $\mathrm{Br}$ I Sports Med 2014:48:1364-9

21 Hamilton B, Whiteley R, Farooq A, et al. Vitamin D concentration in 342 professional football players and association with lower limb isokinetic function. J Sci Med Sport 2014;17:139-43.

22 Ekstrand J, Healy JC, Walden $\mathrm{M}$, et al. Hamstring muscle injuries in professional football: the correlation of MRI findings with return to play. Br I Sports Med 2012;46:112-17

23 Hamilton B, Whiteley $R$, Almusa $E$, et al. Excellent reliability for MRI grading and prognostic parameters in acute hamstring injuries. $\mathrm{Br} / \mathrm{Sports} \mathrm{Med}$ 2014:48:1385-7.

24 Slavotinek JP, Verrall GM, Fon GT. Hamstring injury in athletes: using MR imaging measurements to compare extent of muscle injury with amount of time lost from competition. Am J Radiol 2002:179:1621-8.

25 Verrall GM, Slavotinek JP, Barnes PG, et al. Diagnostic and prognostic value of clinical findings in 83 athletes with posterior thigh injury: comparison of clinical findings with magnetic resonance imaging documentation of hamstring muscle strain. Am J Sports Med 2003:31:969-73.

26 Askling C, Karlsson J, Thorstensson A. Hamstring injury occurrence in elite soccer players after preseason strength training with eccentric overload. Scand J Med Sci Sports 2003;13:244-50.

27 Ekstrand J, Askling C, Magnusson $\mathrm{H}$, et al. Return to play after thigh muscle injury in elite football players: implementation and validation of the Munich muscle injury classification. Br J Sports Med 2013;47:769-74. 